\title{
The Evaluation of GPS techniques for UAV-based Photogrammetry in Urban Area
}

\author{
M. L. Yeh ${ }^{\mathrm{a}, *}, \quad$ Y. T. Chou ${ }^{\mathrm{b}}$, L. S. Yang ${ }^{\mathrm{c}}$ \\ ${ }^{a}$ GIS Research Center, Feng Chia University, Taiwan, milly@gis.tw

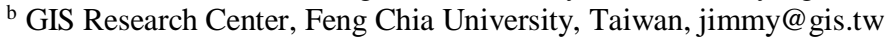 \\ ${ }^{c}$ GIS Research Center, Feng Chia University, Taiwan, lsyang@ gis.tw
}

\section{Commission I, ICWG I/VB}

\section{KEY WORDS: UAV, DSM, Orthophoto, GCP}

\begin{abstract}
:
The efficiency and high mobility of Unmanned Aerial Vehicle (UAV) made them essential to aerial photography assisted survey and mapping. Especially for urban land use and land cover, that they often changes, and need UAVs to obtain new terrain data and the new changes of land use. This study aims to collect image data and three dimensional ground control points in Taichung city area with Unmanned Aerial Vehicle (UAV), general camera and Real-Time Kinematic with positioning accuracy down to centimetre. The study area is an ecological park that has a low topography which support the city as a detention basin. A digital surface model was also built with Agisoft PhotoScan, and there will also be a high resolution orthophotos. There will be two conditions for this study, with or without ground control points and both were discussed and compared for the accuracy level of each of the digital surface models. According to check point deviation estimate, the model without ground control points has an average two-dimension error up to 40 centimeter, altitude error within one meter. The GCP-free RTK-airborne approach produces centimeter-level accuracy with excellent to low risk to the UAS operators. As in the case of the model with ground control points, the accuracy of $\mathrm{x}, \mathrm{y}, \mathrm{z}$ coordinates has gone up $54.62 \%, 49.07 \%$, and $87.74 \%$, and the accuracy of altitude has improved the most.
\end{abstract}

\section{INTRODUCTION}

\subsection{Background}

Landslides are gravitational mass movements of rock, debris or earth [Glade, T., etc., 2012]. They constitute a major natural hazard in all hilly or mountainous regions throughout the world [Hölbling D., 2012]. It is not uncommon for landslides to occur in conjunction with major natural disasters such as floods, earthquakes and volcanic eruptions. Rainfall is a primary trigger of landslides [Raia, S.,etc.,2014] and an example is the recent 2014 Hiroshima landslides triggered by torrential rain [Kurtenbach, E., 2014]. Expanding urbanization and changing land-use practices have increased the incidence of landslide disasters. Although landslide movements are mostly a very local phenomenon, they cause damage to man-made structures and affect infrastructures from local to regional scales or even on a national scale. The floods and landslides in China from May to August 2010 ranked second highest in terms of economic damage caused by natural disasters with US $\$ 18$ billion worth of damage [Hölbling D., 2012, ${ }^{\mathrm{i}}$ Guha-Sapir, D., etc., 2011]. Given the severity of landslides, they are also addressed by the Copernicus emergency management service implemented by the European Commission (EC) with the support from the European Space Agency (ESA) and the European Environment Agency (EEA) [ïEuropean Commission, 2014].

A key parameter in engineering measures and disaster management of landslides is the earthwork volume [iii Chen, Z., etc.,2014]. This parameter can also be used to predict secondary hazards, such as debris flows and dammed lakes. In addition, the earthwork volume is an important index for stability analysis, risk assessment as well as for evaluating the investment needed for dealing with landslides [Chen, Z., etc.,2014; Guzzetti, F., etc., 2005; Chang, C.W., etc., 2011].

Unconventional photogrammetry (UP) has been used to study landslides including the determination of landslide volume. Setting up ground control points (GCPs) and measuring them has been part of the UP and they are necessary to improve the geometry of airborne or space borne images. However, acquiring accurate ground control points via traditional method of onground survey imposes additional time and cost and can take up more than $50 \%$ of the entire project duration. It is particularly challenging and risky to set up ground control points in hazardous and inaccessible locations. SIRIUS pro UAS which uses GNSS-RTK technology achieved 2 to $5 \mathrm{~cm}$ accuracy without physical GCPs. The precise positioning technology allows the image locations to be used as the equivalent of GCPs. This work reports the study of UP measurements for the determination of landslide volume in which the GCPs are measured by means of GNSS and VBS-RTK. They are evaluated against four criteria, namely the earthwork volume accuracy, turnaround time, cost and personnel safety. UP with complete absence of on-ground GCP is evaluated as well.

\section{MATERIALS AND METHODS}

\subsection{Study area}

The study area was the Maple Garden in Taichung City of Taiwan. It is Asia's first large urban sunken green park constructed by the Taichung City Government and it covered an area of 28,000 $\mathrm{m}^{2}$. VBS-RTK Real-Time Kinematic (RTK) systems use global navigation satellite system (GNSS) signals to deliver almost instantaneous positions with centimeter-level accuracy [Riley, S., etc., 2000]. The techniques have been used for a variety of applications such as topographic surveying, 
mining, vehicle guidance and automation [Chang, H., etc.,2014]. Traditional RTK method requires a base and a rover and the maximum range between them is 10 to $15 \mathrm{~km}$. With the establishment of RTK networks, one can work with a RTK rover within these networks without the need of setting up own basestation Network RTK generally requires a recommended minimum of five reference stations with an inter-station spacing of up to $70 \mathrm{~km}$ Network RTK has been implemented in several ways such as Master-Auxiliary Concept (MAC), Virtual Reference Station (VRS) and Flächenkorrekturparameter (FKP) . Each of this technique has its own advantages and short-comings but all of them were designed to achieve high-precision positioning via accurate correction information. This work used the VBS approach.

\subsection{Unconventional photogrammetry}

Photogrammetry is the science of making measurements from photographs and it allows reconstruction of position, orientation, shape and size of objects Kraus, K., 2007. Remote sensing data have been widely used to study landslides. In particular, the use of stereo photogrammetry is gaining momentum as it can produce high-resolution digital terrain model (DTM) or digital elevation model (DEM). It has been used to detect and analyze the spatial distribution of landslides through various sliding activities, such as cracks, scarps, and folds [Herrera, G., et al ., 2009; Zhang, W., et al., 2013,].

Due to the time-critical urgency of natural disasters or major accident relief, much focus has been on the "unconventional photogrammetry" measurement methods and processes, proposed by Tomasi and Kanad [Tomasi, C. and Kanad, T., 1991]. While unconventional photogrammetry is less precise than traditional photogrammetry, it is suitable for emergency response because it does not require camera calibration and can use images from consumer-grade cameras. It can also be applied to historical photos or photos taken by anyone after a disaster. These flexible attributes allow rapid reconstruction of 3D terrain data. Hsiao et al. assessed the earthwork volume of a large-scale slope failure in Taiwan using the unconventional photogrammetry method and the cut-and-fill operation. The discrepancy between their computed result and that provided by the Taiwanese government was only $2.5 \%$ [Hsiao, C., et al. 2011] and such excellent agreement provided further evidence that the cut-and-fill operation and the unconventional photogrammetry technique are able to provide accurate estimation of landslide volumes.

\subsection{Landslide volume calculations}

The general method for calculating the earthwork volume is by evaluating the differences in the DTM elevation before and after a landslide has occurred. Following the work of Chen et al., the landslide's accumulated volume, $V\left(\mathrm{~m}^{3}\right)$ can be obtained using the Height Difference Model.

$V=\int_{a}^{b} S d h$

Where $S(\mathrm{~m} 2)$ is the horizontal area between $a$ and $b$ and $h(\mathrm{~m})$ is the elevation difference between the pre- and postlandslide DTMs, with $a$ and $b$ representation the lowest and the highest elevation, respectively.

Based on Eq. 1, negative values for the Z-coordinates correspond to subsidence or ablation of rock and soil which can be used to derive the removed volume. Likewise, positive values reflect movement where subsidence is combined with the advance of the landslide and these values can be used to derive the accumulated volume of the landslide [Kasperski, J., etc., 2010]. The Height Difference Model is simple yet relatively accurate and it has been used by numerous researchers and adopted by commercial software packages [Du, J. and Teng, H., 2007]. The accuracy of results produced by the model depends very much on the quality of the available data. Uncertainties in the plane position ( $\mathrm{x}$ - and $\mathrm{y}$-coordinates), height ( $\mathrm{z}$-coordinate), and the height baseline difference will reduce the accuracy. Closely related to the Height Difference Model is the cut-and-fill operation which describes the volume change between two grid datasets. It can be thought of as the discrete version of the Height Difference Model and it is implemented in the ArcGIS software.

\subsection{Unmanned aerial systems (UAS)}

Unmanned aerial systems (UAS) refers to the system comprising an unmanned aerial vehicle (UAV), a ground control station (GCS) and the communication data link between the UAV and the GCS [Colomina, I. and Molina P., 2014]. In fact, a UAS is a system of systems. The UAV itself consists of critical components relevant to flight controls, navigation, sensing and orientation. Examples of such components are mechanical servos, auto-pilot system, navigation sensors (gyros) and imaging sensors. Common types of UAV employed in geographic information system (GIS) and landslides research are the multi-rotors, rotary-wing and the fixed-wing aircraft. UAVs are well-suited for surveillance missions around hilly and inaccessible regions though many of the current UAVs are susceptible to poor weather conditions such as strong wind and rains. UAVs have several advantages for acquiring high resolution images. These advantages include a less expensive remote sensing platform, reduced operational costs, improved safety for operators, and a more rapid deployment capability than piloted aircraft [Rango, A., 2009].

The UAV used for this study was a modified Hirobo Freya EX III with custom designed $360^{\circ}$ camera gimbal system. The gimbal system was equipped with gyro-based auto-stabilization and passive vibration dampers. The platform was powered by the O.S. MAX-91HZ glow engine with a displacement of $0.912 \mathrm{cu}$. in. The onboard GPS sensor and inertial measurement unit (IMU) gave ground speed, orientation and gravitational forces information. The Eagle TreeTM FPV (first person view) system allowed the transmission of live video images, as well as relevant telemetry data such as the GPS ground speed and altitude. Maximum flight time was about 30 minutes with a total flying weight of $8.5 \mathrm{~kg}$ and $5.5 \mathrm{~kg}$ payload. The consumer-grade digital camera used in this study was the Canon EOS 550D Mark II with 21.1-megapixel full-frame CMOS sensor [Ackermann, F. 1984]. The radio control and live video links used $72 \mathrm{MHz}$ and $\mathrm{YY} \mathrm{GHz}$ bands, respectively. A more complete list of specifications of the system is as tabulated in Table 1 .

Table 1. UAV system

\begin{tabular}{|c|c|}
\hline Weight & $8.5 \mathrm{~kg}$ \\
\hline Payload & $5.5 \mathrm{~kg}$ \\
\hline Flight time & $30 \mathrm{mins}$ \\
\hline Height & $3000 \mathrm{~m} / 10000 \mathrm{ft}$ \\
\end{tabular}

\subsection{Unconventional photogrammetric workflow}

Once the UAV flight mission was completed, the images from the digital camera were transferred to a desktop computer. Agisoft software was used for the photogrammetric processing and the creation of three-dimensional model (3D reconstruction). Camera calibration was performed using the Agisoft PhotoScan software based on the image correlation algorithm proposed by Ackermann. The absolute orientation process was applied by the affine transformation method and this includes the translations, 
rotations and scaling. The next step involved the automatic generation of the 3D point clouds. At this stage, however, a manual editing process has to be done to remove any obvious outlier. These point clouds were then merged by triangulation to create surface. The resultant outputs from the Agisoft software were the DSM, the corresponding orthophoto, and a 3D viewer animation. The landslide volume was computed using the ArcGIS software. Accuracy of the photogrammetric results was evaluated using the root mean square error (RMSE) estimator. It was done by comparing the coordinates ( $\mathrm{x}$ and $\mathrm{y}$ ) of 10 ground control points and there are the other 10 check points in the photogrammetric model with the coordinates in the measured terrain.

\section{RESULTS AND DISCUSSION}

\subsection{Three-dimensional (3D) reconstruction of UP}

Fig. 3(a) shows the distribution and overlaps of the aerial photographs used in the 3D reconstruction of unconventional photogrammetric. After the triangulation of the model, a digital surface model (DSM) was obtained [Fig. 3(b)]. Texture model was generated by projecting aerial images onto the DSM, as shown in Fig. 3(c). The 3D texture model was then projected onto the x-y plane to obtain the orthophoto [Fig. 3(d)].

Fig. 3(a) shows the 3D surface constructed from the dense point clouds above of 226,000 points. The $3 \mathrm{D}$ texture model was then projected onto the x-y plane to obtain the orthophoto [Fig. 3(d)]. And it has a resolution of $1.3 \mathrm{~cm}$ per pixel and this contributed to a crisp image quality.

(a)

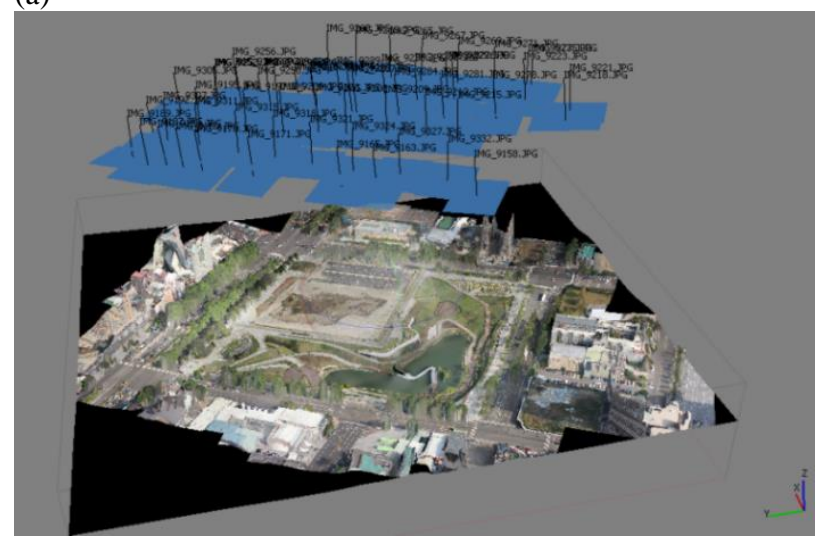

(b)

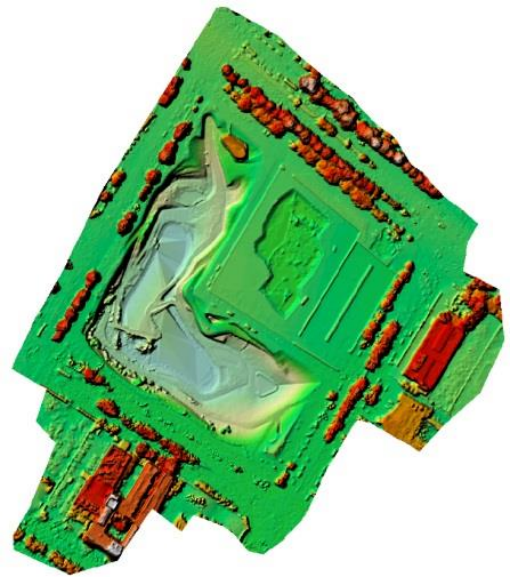

(c)

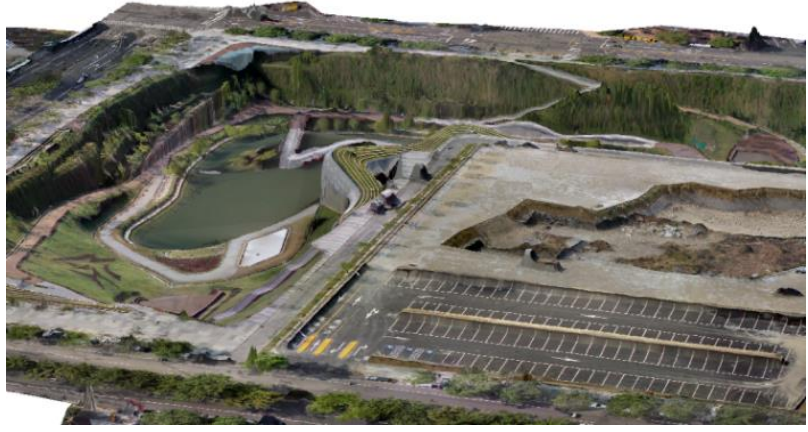

(d)

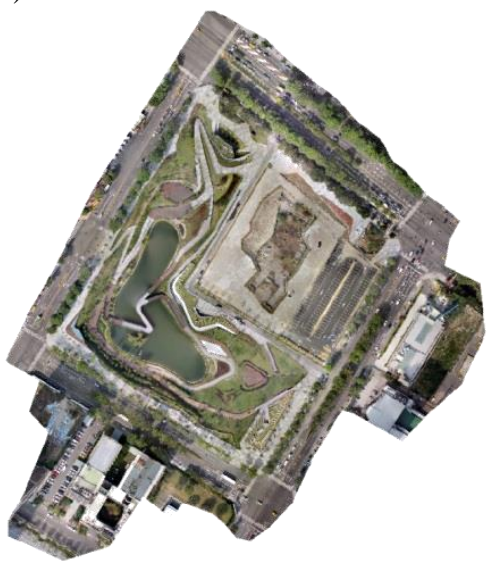

Figure 3. (a) surface constructed from the 3D point clouds (b) digital surface model (c) 3D texture model and (d) orthophoto generated from the projection onto the $\mathrm{x}-\mathrm{y}$ plane.

\subsection{Analysis and Results}

Ten check points in the study area (Points 1 to 10), as indicated in Fig. 4(a and b), were selected based on geographical feature for accuracy analysis. The largest deviations in the $\mathrm{x}$-direction and y-direction observed were $27.09 \mathrm{~m}$ (at Point 4) and $28.54 \mathrm{~m}$ (at Point 3), respectively. These translated into RMSEx and RMSEy values of $19.09 \mathrm{~m}$ and $14.37 \mathrm{~m}$, respectively. The deviation and RMSE values were summarized in Table 2. Perez et al. achieved RMSE of less than $0.1 \mathrm{~m}$ for all the three dimensions with the use of Trimble R6 GPS receiver to measure the coordinates for the check points and ground control point [iv]. $\mathrm{Wu}$ et al. achieved similar accuracy with the deployment of Virtual Base Station Real Time Kinematic Positioning (VBSRTK) processing which allowed real time positioning and hence the actual coordinates of reference control points [v].

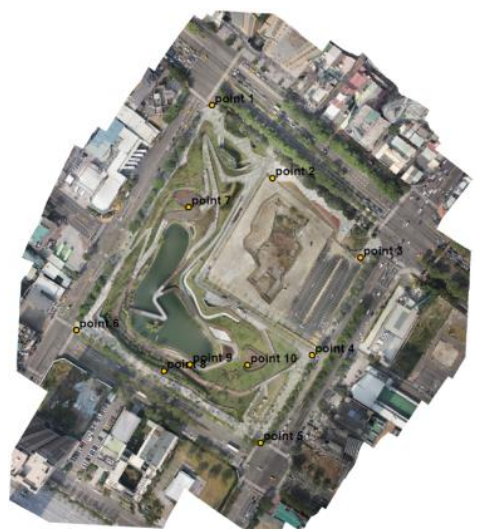

Figure 4 .(a) Ground control points 


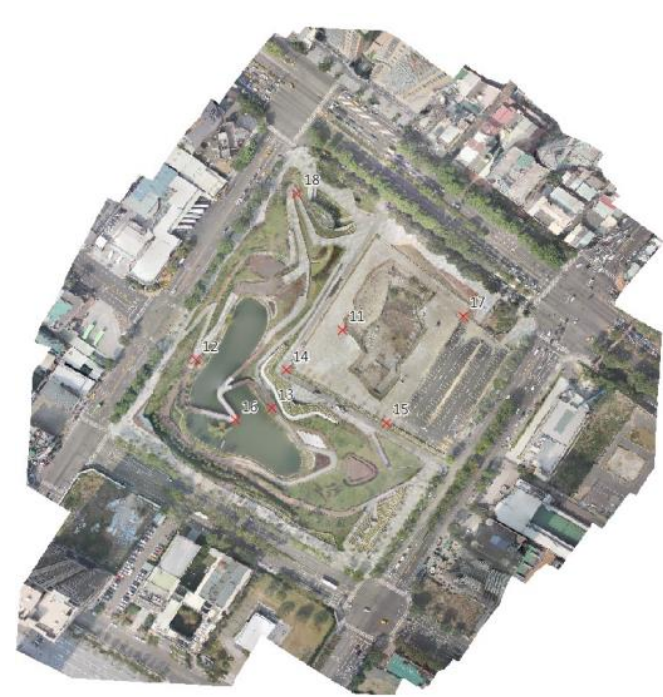

Figure 4 .(b) The check points

Table 1. The ground control points

\begin{tabular}{|c|c|c|c|}
\hline point & $\mathrm{x}$ & $\mathrm{y}$ & $\mathrm{z}$ \\
\hline point1 & 213340 & 2673499 & 82 \\
\hline point2 & 213398 & 2673435 & 92 \\
\hline point3 & 213474 & 2673363 & 83 \\
\hline point4 & 213431 & 2673273 & 79 \\
\hline point5 & 213384 & 2673195 & 86 \\
\hline point6 & 213218 & 2673295 & 83 \\
\hline point7 & 213318 & 2673408 & 76 \\
\hline point8 & 213294 & 2673259 & 82 \\
\hline point9 & 213319 & 2673268 & 74 \\
\hline point10 & 213373 & 2673269 & 75 \\
\hline
\end{tabular}

Table 2 The check points

\begin{tabular}{|c|c|c|c|}
\hline point & $\mathrm{x}$ & $\mathrm{y}$ & $\mathrm{Z}$ \\
\hline point11 & 213370 & 2673370 & 82.02940 \\
\hline point12 & 213275 & 2673354 & 82.50675 \\
\hline point13 & 213324 & 2673318 & 81.96000 \\
\hline point14 & 213333 & 2673342 & 81.69665 \\
\hline point15 & 213398 & 2673303 & 80.66005 \\
\hline point16 & 213297 & 2673305 & 80.09625 \\
\hline point17 & 213449 & 2673381 & 73.05380 \\
\hline point18 & 213338 & 2673469 & 80.34805 \\
\hline
\end{tabular}

\subsection{Results}

To Comparison was performed between the current GCP and the other one case with the check points. As the Table 3, the $\mathrm{x}$ coordinate of the point 16 is $0.5104 \mathrm{~m}$ which is the maximum error value; and the y-coordinate of the point 18 is $0.4451 \mathrm{~m}$. And the point 11 had the max error value which is $1.7936 \mathrm{~m}$. Then calculate RMSE for the $\mathrm{x}, \mathrm{y}$ and $\mathrm{z}$, were the $0.3958 \mathrm{~m} \cdot 0.2739 \mathrm{~m}$. $0.8704 \mathrm{~m}$.

Table 3 The RMSE -only GCP ( Unit: $\mathrm{m}$ )

\begin{tabular}{|c|c|c|c|}
\hline point & X error & Y error & Z error \\
\hline point11 & 0.492645 & 0.433766 & 1.796387 \\
\hline point12 & -0.324218 & -0.27132 & 0.454436 \\
\hline point13 & -0.336988 & 0.13065 & 0.067449 \\
\hline point14 & 0.489021 & -0.045 & -0.709087 \\
\hline point15 & -0.119806 & 0.336337 & 0.331558 \\
\hline point16 & 0.510438 & -0.070138 & 0.259411 \\
\hline point17 & -0.336657 & -0.056455 & -1.263049 \\
\hline point18 & -0.40563 & -0.445143 & 0.589571 \\
\hline RMSE & $\mathbf{0 . 3 9 5 8}$ & $\mathbf{0 . 2 7 3 9}$ & $\mathbf{0 . 8 7 0 4}$ \\
\hline
\end{tabular}

Table 4 The RMSE with check points (unit: $\mathrm{m}$ )

\begin{tabular}{|c|c|c|c|}
\hline point & X error & Y error & Z error \\
\hline point11 & 0.063975 & 0.115639 & 0.163563 \\
\hline point12 & -0.10141 & -0.098174 & -0.101445 \\
\hline point13 & -0.047651 & -0.02078 & 0.037167 \\
\hline point14 & 0.286053 & -0.04252 & -0.10264 \\
\hline point15 & -0.019843 & 0.212839 & 0.045787 \\
\hline point16 & 0.22984 & 0.117537 & -0.138581 \\
\hline point17 & -0.12359 & 0.007615 & -0.001901 \\
\hline point18 & -0.301724 & -0.266749 & 0.144551 \\
\hline RMSE & $\mathbf{0 . 1 7 9 6}$ & $\mathbf{0 . 1 3 9 5}$ & $\mathbf{0 . 1 0 6 7}$ \\
\hline
\end{tabular}

\subsection{Comparison study}

The study used the ten check points to improve the error of DSM. Then to view the result, all the $\mathrm{X}, \mathrm{Y}$ and $\mathrm{Z}$ that RMSE value were decreased. The three value $-X: 0.2162 \mathrm{~m}(54.62 \%), \mathrm{Y}: 0.1344 \mathrm{~m}$ $(49.07 \%)$ and Z: $0.7637 \mathrm{~m}(87.74 \%)$. Shown $\mathrm{d}$ as the ta

Table 2 RMSE comparison study (unit: $\mathrm{m}$ )

\begin{tabular}{|c|c|c|c|}
\hline RMSE & X error & Y error & Z error \\
\hline 1 & 0.3958 & 0.2739 & 0.8704 \\
\hline 2 & 0.1796 & 0.1395 & 0.1067 \\
\hline $\begin{array}{c}\text { RMSE } \\
\text { decresed }\end{array}$ & 0.2162 & 0.1344 & 0.7637 \\
\hline
\end{tabular}




\begin{tabular}{|l|l|l|l|}
\hline Percentage & $54.62 \%$ & $49.07 \%$ & $87.74 \%$ \\
\hline
\end{tabular}

\section{CONCLUSIONS}

The study area is an ecological park that has a low topography which support the city as a detention basin. A digital surface model was also built with Agisoft PhotoScan, and there will also be a high resolution orthophotos. There will be two conditions

Glade T., Anderson M., Crozier M. J. Landslide Hazard and Risk, 2012. John Wiley \& Sons Ltd., Chichester, West Sussex, England, 810.

Hölbling D., Füreder P., Antolini F., Cigna F., Casagli N., Lang S. A semi-automated object-based approach for landslide detection validated by Persistent Scatterer Interferometry measures and landslide inventories. Remote Sensing. 2012. 4(12) 1310-1336.

Raia,S., M. Alvioli, M. Rossi, R. L. Baum, J. W. Godt, F. Guzzetti. Improving predictive power of physically based rainfall-induced shallow landslide models: a probabilistic approach. arXiv. 2014. 1305.4803

Kurtenbach E. 2014: Hills Near Hiroshima Give Way, Killing Dozens. [http://www.huffingtonpost.com/2014/08/19/japanlandslides-2014_n_5693242.html]

Guha-Sapir D., Vos F., Below R., Ponserre S. Annual disaster statistical review 2010: The numbers and trends; Center for research on the Epidemiology of Disasters (CRED). 2011 pp. 41-42.

European Commission. 2014: Copernicus Emergency Management Service

[http://emergency.copernicus.eu/mapping/ems/whatcopernicus]

Chen Z., Zhang B., Han Y., Zuo Z., Zhang X. Modeling Accumulated Volume of Landslides Using Remote Sensing and DTM Data. Remote Sensing. 2014. 6(2) 1514-1537.

Guzzetti F., Reichenbach P., Cardinali M., Galli M., Ardizzone F. Probabilistic landslide hazard assessment at the basin scale. Geomorphology. 2005. 72(1-4) 272-299.

Chang C. W. , Lin P, Tsai C. Estimation of sediment volume of debris flow caused by extreme rainfall in Taiwan. Engineering Geology. 2011. 123(1) 83-90.

Riley S., Talbot N., Kirk G., 2000: A new system for RTK performance evaluation. Position Location and Navigation Symposium, IEEE. 231-236, San Diego, CA. for this study, with or without ground control points and both were discussed and compared for the accuracy level of each of the digital surface models. According to check point deviation estimate, the model without ground control points has an average two-dimension error up to 40 centimeter, altitude error within one meter. The GCP-free RTK-airborne approach produces centimeter-level accuracy with excellent to low risk to the UAS operators. As in the case of the model with ground control points, the accuracy of $\mathrm{x}, \mathrm{y}, \mathrm{z}$ coordinates has gone up $54.62 \%, 49.07 \%$, and $87.74 \%$, and the accuracy of altitude has improved the most.

Chang H., Ge L., Rizos C. 2014: Assessment of digital elevation models using RTK GPS

Kraus K., 2007: Photogrammetry: Geometry from Images and Laser Scans. Walter de Gruyter, 459.

Herrera G., Davalillo J. C., Mulas J., Cooksley G., Monserrat O., Pancioli, V. Mapping and monitoring geomorphological processes in mountainous areas using PSI data: Central pyrenees case study. Nat. Hazards Earth Syst. Sci. 2009. 9(5) $1587-1598$.

Zhang W., Lin J. Peng J., Lu Q. Estimating Wenchuan Earthquake induced landslides based on remote sensing. International Journal of Remote Sensing. 2010. 31(13) 34953508 .

Tomasi C., Kanade T. Detection and Tracking of Point Features. 1991. Carnegie Mellon University, Pittsburgh, PA.

Hsiao C., Hsieh P., Chi S. Assessing Volume Earthwork by Using Unconventional Photogrammetry. Proceedings of the Second World Landslide Forum, 3-7 October 2011, Rome.

Kasperski J., Delacourt C., Allemand P., Potherat P., Jaud M., Varrel, E. Application of a Terrestrial Laser Scanner (TLS) to the study of the Séchilienne landslide (Isère, France). Remote Sens. 2010. 2(12) 2785-2802.

Du J., Teng H. 3D laser scanning and GPS technology for landslides earthwork volume estimation. Autom. Constr. 2007. 16(5) 657-663.

Colomina I., Molina P. Unmanned aerial systems for photogrammetry and remote sensing: A review ISPRS Journal of Photogrammetry and Remote Sensing. 2014. 92 79-97.

Rango A. Unmanned aerial vehicle-based remote sensing for rangeland assessment, monitoring, and management. Journal of Applied Remote Sensing. 2009. 3, 033542.

Ackermann F. Digital image correlation: performance and potential application in photogrammetry. Photogrammetric Record. 1984. 11(64) 429-439.

Pérez M., Agüera F., and Carvajal F. Low cost surveying using an unmanned aerial vehicle. Int. Arch. Photogramm. Remote Sens. Spatial Inf. Sci. 2013. XL-1/W2, 311-315. 
Wu, C.T. , 2013, Using UAV and VBS-RTK for rapid reconstruction of environmental $3 \mathrm{D}$ elevation data of the Typhoon Mrakot disaster area and disaster scale assessment. Jour nal of Chinese Soil and Water Conservation. 2013. 44(1) 23-33. 